\title{
POLÍTICAS “CRISTOFASCISTAS” E "POLÍTICAS DOS TERREIROS” NO RIO GRANDE DO SUL: A POLÊMICA DO SACRIFÍCIO DE ANIMAIS NAS RELIGIÓEES DE MATRIZ AFRICANA ${ }^{1}$
}

\author{
Ari Pedro Oro ${ }^{2}$
}

Resumo: Em duas oportunidades, em 2003 e em 2015, dois deputados evangélicos de perfil pentecostal conservador da Assembleia Legislativa do Rio Grande do Sul apresentaram e tentaram aprovar projetos de lei que visavam proibir o sacrifício de animais nas religióes de matriz africana do Estado (Batuque, Quimbanda, Linha Cruzada). Tais iniciativas ensejaram forte mobilização política por parte dos afrorreligiosos. Inspirado no texto de Ana Paula Mendes de Miranda analiso os eventos a partir de duas categorias por ela empregadas, a saber, políticas "cristofascistas", empreendidas pelos deputados evangélicos, e "políticas dos terreiros", levadas a efeito pelos afrorreligiosos e pelos membros dos movimentos negros que apoiaram a causa. As mobilizaçóes políticas "dos terreiros" foram decisivas não somente para evitar as aprovaçóes dos referidos projetos de lei, mas, também, apoiadas por uma parcela do parlamento e do judiciário gaúchos, foram muito importantes para que o tema do sacrifício de animais em rituais religiosos chegasse ao Supremo Tribunal Federal, o qual decidiu por unanimidade pela sua constitucionalidade.

Palavras-chave: religiôes afro-gaúchas; políticas cristofascistas; políticas dos terreiros; sacrifício de animais.

"CHRISTOFASCIST POLITICS" AND "TERREIROS POLITICS" IN RIO GRANDE DO SUL. THE CONTROVERSY OF ANIMALS

SACRIFICE IN AFRICAN-BASED RELIGIOUS

Abstract: On two occasions, in 2003 and in 2015, two evangelical deputies with a conservative Pentecostal profile of the Legislative Assembly of Rio Grande do Sul

1 Como citar: ORO, Ari Pedro. Políticas "cristofascistas" e "políticas dos terreiros" no Rio Grande do Sul: a polêmica do sacrifício de animais nas religióes de matriz africana. Debates do NER, Porto Alegre, ano 21, n. 40, p. 163-184, 2021.

2 Doutor em Antropologia, pesquisador do CNPq e professor do Programa de Pós-graduação em Antropologia Social da Universidade Federal do Rio Grande do Sul, Porto Alegre, Brasil. E-mail: arioro@uol.com.br. ORCID: https://orcid.org/0000-0002-6121-8711.

Debates do NER, Porto Alegre, ANo 2I, N. 40, P. I63-I84, AGo./DeZ. 202 I 
presented and tried to approve bills that aimed at banning the sacrifice of animals in African-based religions (Batuque, Quimbanda, Linha Cruzada). Such iniciatives gave rise to strong political mobilization on the part of the practitioners of Afro-Brazilian religions. Inspired by the text by Ana Paula Mendes de Miranda, I analyze the events based on two categories employed by her, namely, "Christofascist politics", undertaken by evangelical deputies, and "terreiros politics", carried out by the practitioners of Afro-Brazilian religions and by members of the black movements who supported the cause. The political mobilizations "from the terreiros" were decisive not only to avoit the approval of the mentioned bills, but also, supported by a portion of the Gaucho parliament and judiciary, were very important for the subject of animal sacrifice in religious rituals reach the Federal Supreme Court, which unanimously decided on its constitutionality.

Keywords: afro-gaúchas religions; "cristofascist politics"; "terreiros politics"; animals sacrifice.

O texto A "politica dos terreiros" contra o racismo religioso e as politicas "cristofascistas" de Ana Paula Mendes de Miranda, apresenta uma visão multidimensional de questóes cruciais que afetam, na atualidade, as religióes de matriz africana em nosso país. Trata-se de um texto denso, ao mesmo tempo teórico e recheado de dados empíricos, no qual a autora apresenta estratégias de mobilização dos grupos afrorreligiosos enquanto uma modalidade de política "dos terreiros" diante da violência concreta e simbólica promovida por políticas "cristofascistas".

Assumo o texto de Ana Paula de Miranda como inspiração para revisitar um fato, por ela mesma referido na nota 26 , que consistiu numa dupla tentativa, ocorridas em 2003 e em 2015, na Assembleia Legislativa do Estado Rio Grande do Sul, de proibir legalmente as religióes de matriz africana a realizarem sacrifícios de animais. Após amplos debates políticos e jurídicos locais, a questão chegou ao Supremo Tribunal Federal que decidiu por unanimidade pela constitucionalidade do sacrifício de animais em rituais religiosos ${ }^{3}$.

3 Adianto, porém, que este texto, pela limitação de espaço, não irá dar conta do conjunto de variáveis que envolvem as diversas forças políticas em confronto, uma vez que a bibliografia já produzida sobre o tema é importante, como vou apontar mais à frente.

Debates do NER, Porto Alegre, ANo 2I, N. 40, P. I63-I84, Ago./Dez. 202 I 
Posto que ambas as iniciativas partiram de deputados evangélicos de perfil pentecostal conservador, entendo ser possível inscrevê-las como sendo exemplos de políticas "cristofascistas", as quais, por sua vez, desencadearam várias mobilizaçôes políticas "dos terreiros" para se opor não somente a uma prática de intolerância religiosa mas de racismo religioso ${ }^{4}$.

Tomo como referência e sugestão epistemológica para iluminar os eventos ocorridos em torno da proibição do sacrifício de animais no Rio Grande do Sul sobretudo uma frase, constante na conclusão do texto de Miranda, comentado neste volume, a saber: "Se de um lado há um acirramento dos ataques às religiōes afro motivados por políticas "cristofascistas", de outro há o surgimento de políticas "dos terreiros", que estimulam os sujeitos a refletir e agir, em consonância com seus interesses, permitindo ampliar a discussão acerca da dissimulaçấo das práticas de discriminação no Brasil, de modo a cobrar, principalmente, dos órgãos públicos que náo se pode mais ser omisso diante desses casos, cada vez mais graves".

Antes, porém, de entrar diretamente no foco do texto entendo ser necessário apresentar sucintamente o campo afrorreligioso sul-riograndense 5 .

\section{O Rio Grande do Sul Afrorreligioso}

O Rio Grande do Sul produziu historicamente sobre si mesmo uma auto-imagem, com repercussôes para fora dele, de ser um Estado branco, colonizado e habitado por imigrantes europeus e por gaúchos, invisibilizando e mesmo excluindo os negros e os indígenas, dois grupos étnicos

4 No texto de Miranda há uma análise minuciosa sobre a polarização entre os termos "intolerância" e "racismo" enquanto "duas faces de um problema social e público". Aqui os termos estáo justapostos porque ambos aparecem nas múltiplas vozes afrorreligiosas enquanto termos êmicos, embora o segundo seja portador de uma potência política particular.

5 Uso aqui o termo afrorreligioso no sentido amplo, que faz referência aos membros das religiōes afro-brasileiras, praticantes ou não, que atuam direta ou indiretamente em movimentos sociais ou políticos.

Debates do NER, Porto Alegre, ano 2I, N. 4O, P. I63-I 84, AGo./DEZ. 202 I 
que historicamente prestaram inestimável contribuição para a construção da pujança do estado (Oliven, 2006).

$\mathrm{Na}$ atualidade, cerca de 14\% dos habitantes do Rio Grande do Sul são afro-descendentes que têm dado a ele, além da histórica mão de obra para sustentar a sua economia (Silva, Santos, Carneiro, 2008), uma importante contribuição sócio-cultural, feita da incorporação no vernáculo de centenas de palavras africanas, majoritariamente bantu (Laytano, 1936) e sobretudo da inscrição, nesta sociedade, de manifestações sócio-religiosas, com destaque para as religióes afro-gaúchas ${ }^{6}$.

Quando os dados do último Censo do IBGE de 2010 foram divulgados, causou certa estranheza nacional o fato de este estado "branco" ter aparecido como o detentor do maior número de indivíduos no país que, em termos proporcionais, tenham se declarado pertencentes às religióes de matriz africana.

De fato, segundo o Censo de 2010, enquanto a média nacional de identificação de pertencimento ao segmento afrorreligioso é de 0,3\% da população, no Rio Grande do Sul essa porcentagem sobe para 1,47\%.

6 Também chamadas de religióes afro-riograndenses, constituem um complexo religioso formado por três expressôes dominantes, assim denominadas emicamente: Batuque (ou Nação, que cultua orixás), Linha Cruzada (ou Quimbanda, que venera Exus e Pombagiras) e Umbanda (ou Linha Branca, que cultua Pretos-Velhos, Caboclos e "bejis"). Há termos genéricos para se referir a elas, uns advindos de fora desse campo religioso, sendo, por isso mesmo, portadores de certo preconceito, como "saravá" e "macumba", e outros empregados no interior do campo afrorreligioso, como "religiáo", "povo de religião", "nação".

Embora expostas, para fins didáticos, como expressóes afrorreligiosas "separadas", é válida para o campo afrorreligioso do Rio Grande do Sul a observação feita por Stefania Capone para o mesmo campo mais amplamente, ou seja, as "diferentes" religiōes afro-brasileiras se encontram num "continuum", feito de práticas e narrativas possíveis e necessárias (Capone, 2004).

Mesmo assim, a expressão "religião de matriz africana", utilizada no texto, contempla parcialmente a "Umbanda de linha branca" não somente porque ela nasceu no Brasil e cultua entidades inscritas em solo brasileiro, mas porque não realiza rituais sacrificiais que envolvem animais (Machado, 2015).

Debates do NER, Porto Alegre, Ano 2 I, N. 40, P. I63-I 84, Ago./Dez. 202 I 
Em termos comparativos, o índice de pertencimentos afrorreligiosos no estado do Rio de Janeiro é de $0,89 \%$ e da Bahia de 0,34\%, igualando a São Paulo, que também alcança 0,3\%, constituindo-se o Rio de Janeiro como o segundo Estado com maior representatividade afrorreligiosa no país. Os demais estados de reconhecida existência das religióes de matriz africana apresentaram, sempre segundo o Censo de 2010, os seguintes índices: Pernambuco 0,14\%, Pará 0,07\% e Maranhão, 0,06\%.

Evidentemente que esses dados, embora advindos do Censo, não podem ser tomados como verdade científica, mesmo porque outras pesquisas revelaram que, de uma forma geral, esses números sobre os pertencimentos afrorreligiosos estáo subestimados ao menos pela metade. Lembremos, neste sentido, da advertência feita há anos atrás por R. Prandi, para quem as incongruências estatísticas se devem

às circunstâncias históricas nas quais essas religiôes se constituíram no Brasil e ao seu caráter sincrético daí decorrente [...]. Por tudo isto, é muito comum, mesmo atualmente, quando a liberdade de escolha religiosa já faz parte da vida brasileira, muitos seguidores das religióes afro-brasileiras ainda se declararem católicos (Prandi, 2003, p. 16).

Mesmo assim, como escrevi em outro lugar (Oro, 2012), sugiro algumas hipóteses para explicar a importante incidência de indivíduos que expressam o seu pertencimento identitário afrorreligioso no Rio Grande do Sul. Elas se inscrevem na história e na cultura religiosa deste estado 7 . Em primeiro lugar, o fato de a diversidade religiosa estar aqui implantada há bastante tempo - devido sobretudo à imigraçáo germânica luterana, iniciada em 1824 e às religiosidades indígenas -, o que produziu uma certa predisposição cultural de aceitação da alteridade religiosa e de expressão social dos pertencimentos, embora se saiba que a identificação social às religiốes de matriz africana nunca tenha sido tranquila devido, sobretudo, à carga de

7 Não estou discorrendo sobre as razôes da adesão dos habitantes do Rio Grande do Sul às religióes afro-brasileiras, mas sobre as razóes da explicitação social do seu pertencimento a essas religiôes.

Debates do NER, Porto Alegre, ANo 2I, N. 40, P. I63-I84, Ago./DeZ. 202 I 
preconceitos que incidem sobre ela. Em segundo lugar, há no Rio Grande do Sul uma tradição de afirmação social das opções individuais que geram identidades sociais, nos campos da política, das ideologias, do esporte, extensiva também ao campo religioso, predispondo, novamente, os sujeitos a expressarem publicamente as suas opçóes religiosas, entre elas, a afrorreligiosa. Em terceiro lugar, no Rio Grande do Sul a expressão social do pertencimento afrorreligioso pode estar relacionada ao fato de essas religióes talvez serem um pouco menos estigmatizadas do que em outras regióes do país, uma vez que sua estruturação e reprodução não detém a longevidade constatada em outras regiôes do país. Esta hipótese se baseia na consideração de R. Prandi (2003), para quem haveria no Brasil uma relação entre maior ou menor preconceito contra as religióes afro-brasileiras e mais longa ou mais recente implantação das mesmas nas diferentes regiôes do país. Enfim, a expressão pública do sentimento de pertencimento afrorreligioso no Rio Grande do Sul também se deveu ao esforço político de conscientização, conduzido por líderes afrorreligiosos e do movimento negro deste estado nos Censos de 2000 e 2010, sintetizado no slogan: "quem é de axé diz que é". 8

No entanto, apesar da relativização feita acima, a partir da observação de Prandi, é importante frisar que o racismo contra as religióes de matriz africana sempre foi forte no Rio Grande do Sul (Mello, 1995). A título de exemplo, menciono uma narrativa recorrente no meio afrorreligioso de Porto Alegre acerca de dois graves momentos de repressão. O primeiro ocorreu entre os anos de 1925 e 1929, quando o delegado Freitas Lima comandava policiais para os sábados à noite fazerem uma ronda e, via de regra, encontravam justificativas para invadir alguns terreiros. Dez anos mais tarde, durante o Estado Novo, mais especificamente em 1937, o general Manoel Daltro Filho, interventor federal no Rio Grande do Sul, desencadeou "um período tenebroso, com o sistemático fechamento, pela política, de muitos dos templos (afrorreligiosos), com prisóes e violência por parte dos policiais"

8 Segundo Cunha (2017, p. 33), esta mobilização tinha como objetivo "fazer o Povo de Terreiro visível para a elaboração de políticas públicas nacionais e estaduais, qualitativa e quantitativamente”.

Debates do NER, Porto Alegre, Ano 2 I, N. 40, P. I63-I84, Ago./DeZ. 202 I 
(Correa, 1998, p. 224) ${ }^{9}$. Porém, a comunidade batuqueira reagiu às repressóes desencadeadas pelo general realizando rituais, vulgarmente chamados de "feitiços coletivos". Coincidentemente ou não, o general adoeceu e faleceu quatro meses após assumir o governo.

Esses relatos revelam apenas dois momentos, localizados espacialmente, de um histórico de repressôes concretas sofridas pelas religióes afro-gaúchas. $\mathrm{Na}$ sequência, o foco será outra forma de agressão contra estas mesmas religiôes, produzida por agentes políticos e jurídicos do estado, que tentaram destruir um poderoso componente do seu patrimônio simbólico.

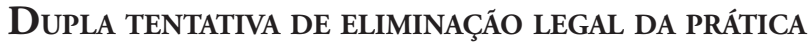 SACRIFICIAL NAS RELIGIÓES DE MATRIZ AFRICANA}

Nas religióes de matriz africana o sacrifício de animais detém importante centralidade devido aos significados simbólicos a ele atribuídos ${ }^{10}$. De fato, ao lado da possessão o sacrifício consiste num dos seus fundamentos ontológicos, ou como diz Goldman (1987), sacrifício e possessão são os dois pilares sobre os quais se assenta a estrutura religiosa afro-brasileira. É o momento sagrado por excelência, em que animais de "dois pés" (aves como pombas e galináceos) ou de "quatro pés" (ovinos, suínos, bovinos e caprinos), são imolados como oferendas para entidades sobrenaturais, obedecendo a intencionalidades específicas. Através dos animais imolados há trocas simbólicas entre as divindades e os membros da comunidade religiosa. Ou seja, a vítima sacrificial realiza a mediação entre os seres

9 A este respeito, Norton Correa colheu o seguinte depoimento do batuqueiro Ademar do Ogum: "A versão que eu ouvia é que o Daltro veio pra cá com a intenção de acabar com todos os batuqueiros e com todas as casas de religiāo (afro-brasileira) aqui dentro do Rio Grande do Sul” (Ibid., p. 224).

Evidentemente que neste período, mas não somente, semelhante violência contra as religiōes de matriz africana aconteceram em muitas outras regióes brasileiras.

${ }^{10}$ Reitero que o sacrifício de animais é realizado nas variantes denominadas Batuque (Nação) e Linha Cruzada (Quimbanda), mas não na chamada Umbanda de Linha Branca. 
humanos e os seres espirituais, produzindo vínculos e alianças mútuas, ao mesmo tempo em que suas carnes sacralizadas são consumidas pelos fiéis como alimento físico e espiritual, isto é, como fonte de força e vida, ou seja, de axé (Tadvald, 2007). Assim sendo, "o sacrifício é um momento especial de fusão de destinos e renascimentos em uma unidade simultaneamente animal, humana e divina” (Anjos, 2015).

Apesar de toda esta intensidade simbólica associada ao sacrifício de animais, assegurada pelo direito à liberdade religiosa previsto na constituição federal, nos anos de 2003 e 2015 transitaram na Assembleia Legislativa do Estado do Rio Grande do Sul dois projetos de lei que tentaram proibir a realização daquele ritual.

O primeiro projeto, de autoria do deputado e pastor da Igreja do Evangelho Quadrangular Manoel Maria dos Santos, propunha a criação do Código Estadual de Proteçáo aos Animais para o Estado do Rio Grande do Sul e nele, em seu artigo segundo, constava a vedação para "realizar espetáculos, esporte, tiro ao alvo, cerimônia religiosa, feitiço, rinhadeiros, ato público ou privado, que envolvam maus tratos ou a morte de animais...". Obviamente que os afrorreligiosos entenderam a artimanha e imediatamente se mobilizaram - como veremos mais adiante - provocando a reformulação do artigo segundo, que foi aprovado com a seguinte redação: "é vedado ofender ou agredir fisicamente os animais, sujeitando-os a qualquer tipo de experiência capaz de causar sofrimento ou dano...”.

O projeto de Lei recebeu o número 11.915 e foi sancionado em maio de 2003, pelo então governador Germano Rigotto. Porém, apesar da nova redação os afrorreligiosos continuaram apreensivos e se mantiveram mobilizados ${ }^{11}$. Acionaram o deputado estadual Edson Portilho, o único afrodescendente presente no parlamento, a apresentar novo Projeto de Lei, PL 282/2003, o qual abria a seguinte exceção ao artigo 2. ${ }^{\circ}$ da Lei n. 11.915: "Para o exercício de

${ }^{11}$ Isto porque, no dizer do babalorixá de Porto Alegre Pedro da Oxum Docô, "o texto é dúbio e dá margem ao preconceito. Como é que os juízes vão interpretar a lei?" (Jornal Zero Hora, Porto Alegre, 21 de julho de 2003. In: Leistner, 2020). 
cultos religiosos, cuja liturgia provém de religióes de matriz africana, somente poderão ser utilizados animais destinados à alimentação humana, sem utilização de recursos de crueldade para a sua morte". Este novo projeto foi aprovado na Assembleia legislativa em 29 de junho de 2003 e sancionado pelo governador em julho de 2003.

Mas, em outubro do mesmo ano, a lei de autoria do deputado Portilho foi levada na instância jurídica pelo Procurador-Geral de Justiça, Roberto Bandeira Pereira, o qual entrou com uma Ação Direta de Inconstitucionalidade (ADIN) $)^{12}$, requerendo a retirada do artigo 2. ${ }^{\circ}$. Somente em 18 de abril de 2005 a constitucionalidade da lei foi aprovada pelo Tribunal de Justiça do Estado. Como veremos logo a seguir, o Ministério Público Estadual acionou o STF, interpondo um Recurso Extraordinário contra a decisão do Tribunal de Justiça deste estado que autorizou o sacrifício de animais.

Esta atitude da Procuradoria Geral da República escancara que além dos religiosos evangélicos o Estado também se mostrou ser um agente de discriminação e de violência contra as religiões de matriz africana.

Dez anos mais tarde, em fevereiro de 2015, outra deputada evangélica, Regina Becker Fortunati (PDT), membro da Igreja Batista Filadélfia, ativista na defesa dos animais e detentora de uma "pertença religiosa que se caracteriza historicamente como persecutória à liturgia afrorreligiosa" (Tadvald e Gonzaga, 2017, p. 258), protocolou na Assembleia Legislativa do Rio Grande do Sul novo projeto de lei (P121/2015) que buscava revogar a autorização legal para que no Código Estadual de Proteção aos Animais os religiosos de matriz africana pudessem realizar imolaçóes ritualísticas com animais. No projeto da deputada ficaria restabelecida a redação original de 2003 do Código Estadual de Proteção aos Animais, que dizia: "É vedado: realizar espetáculos, esporte, tiro ao alvo, cerimônia religiosa, feitiço, rinhadeiros, ato público ou privado, que envolvam maus tratos ou a morte de animais".

12 "A alegação era de que esse dispositivo seria inconstitucional porque se tratava de matéria penal, de competência legislativa privativa da Uniāo” (Tadvald e Gonzaga, 2017, p. 258).

Debates do NER, Porto Alegre, ANo 2I, N. 40, P. I63-I84, Ago./Dez. 202 I 
Como dissemos em outro texto (Oro, Carvalho, Scuro, 2017, p. 237), os argumentos acionados desta vez para eliminar o referido artigo recaíram sobre três eixos, a saber: "a) a necessidade de proibir a morte cruel dos animais durante os rituais; b) a visão evolucionista que considera os rituais sacrificiais como práticas primitivas; c) (...) as condiçôes de abate e o descarte dos animais, que não seguiriam a legislação sanitária”.

Depois de quatro meses de discussóes na Comissão de Constituição e Justiça, que envolveu muitas mobilizaçóes e debates, dentro e fora da Assembleia Legislativa, o projeto de lei foi derrotado e arquivado naquela comissão, saindo os afrorreligiosos novamente vitoriosos ${ }^{13}$.

O Recurso Extraordinário interposto pelo Ministério Público do Rio Grande do Sul junto ao STF contra a decisão do Tribunal de Justiça do Estado que autorizou o sacrifício de animais, como mencionei atrás, começou a ser julgado na Suprema Corte em agosto de 2018 e foi finalizado em 28 de março de 2019, com decisão unânime dos seus membros favorável à constitucionalidade do sacrifício de animais nos cultos religiosos. A tese produzida pelo STF foi a seguinte: "É constitucional a lei de proteção animal que, a fim de resguardar a liberdade religiosa, permite o sacrifício ritual de animais em cultos de religióes de matriz africana".

Em seu texto, Ana Paula de Miranda, apoiada em Hoshimo e Bueno (2019), afirma que "mesmo náo tendo sido citado expressamente pelas(os) ministras(os) do STF o termo racismo, a decisão foi considerada histórica ao tratar da violência contra as matrizes africana como uma das facetas do racismo estrutural".

De fato, é importante sublinhar que essa decisão do STF, confirmando a constitucionalidade do sacrifício de animais nas religióes de matriz africana,

${ }^{13}$ Para mais informações sobre os mencionados projetos de leis e as polêmicas por eles provocadas ver Oro, 2005; Tadvald, 2007; Anjos, 2015; Machado 2015; Oro, Carvalho e Scuro, 2017; Tadvald e Gonzaga 2017. 
não se restringe ao Rio Grande do $\mathrm{Sul}^{14} \mathrm{e}$ é reveladora de mais uma forma de racismo contra essas religiôes em particular e contra um grupo étnico-racial mais amplamente.

\section{Política CRISTOFAsCista?}

Como aponta Ana Paula Miranda, atribui-se à teóloga alemã Dorothee Sölle (1970) a criação do termo "cristofascismo". Ele deriva da fusão de cristianismo com fascismo e se refere às relaçóes mantidas entre igrejas cristãs e membros do partido nazista, aquelas contribuindo para a consolidação do estado de exceção. No dizer de Sanchez e Arruda (2020), o termo está sendo cada vez mais utilizado para descrever o atual rumo das políticas neoconservadoras que unem religião e política. Mais especificamente, "cristofascismo" remete para a junção ao ideário político de valores cristãos conservadores, ao mesmo tempo em que cria inimigos a serem combatidos e até mesmo eliminados, posto que não se adequam ao seu padrão de moralidade.

É no seu sentido amplo, que remete à imbricação entre política de direita e cristianismo conservador, que defende suas doutrinas religiosas como verdade que deve servir de suporte para o conjunto da sociedade, não admitindo e aceitando alteridade religiosa, que o termo "cristofascismo" é trazido para o estudo em tela. Ele pode ser acionado para se entender a insistência de dois políticos religiosos, isto é, deputados evangélicos, do parlamento gaúcho, que tentaram instituir um dispositivo legal para eliminar um dos fundamentos das religióes de matriz africana, mesmo que isto significasse

${ }^{14}$ A decisão do STF "tem repercussão geral e deverá ser seguida por juízes e tribunais de todo o país", G1, Brasília, DF, 28 de mar. de 2021. Disponível em: https://g1.globo. com/política/noticia/2019/03/28/stf-decide-que-e-constitucional-sacrificar-animais-em-cultos-religiosos.ghtml. Acesso em: 10 maio 2021.

Para uma análise específica do julgamento do referido Recurso Extraordinário no STF, com os argumentos usados pelos ministros da Corte, ver os artigos de Cristina G. B. de Oliveira (2019) e de Thiago de Azevedo Pinheiro Hoshino e Winnie Bueno (2019). 
atentar contra o dispositivo constitucional da liberdade de crença, previsto na Constituição de 1891 e reforçada na Constituição de 1988.

Com efeito, ao invés de procurar entender o significado e a lógica do sacrifício, os deputados evangélicos em questão e todos os que os acompanharam, abordaram o ritual exclusivamente de um ponto de vista reducionista e evolucionista. Para eles, trata-se de uma prática que imprime sofrimento aos animais e que constitui uma expressão de primitividade. Evidentemente que neste tema esses deputados constituíram-se em porta-vozes de uma parcela significativa da sociedade brasileira que transcende os evangélicos e alcança fortemente também os católicos, que, de um lado, alimentam todo um conjunto de estigmas depreciativos acerca dos cultos afro-religiosos (Maggie, 1992) e que, de outro lado, sustentam que o único modelo legítimo de religião é aquele inscrito historicamente na sociedade brasileira, ou seja, o cristianismo, com suas variantes católica e evangélica (Giumbelli, 2008). Assim sendo, obviamente que se trata de uma arrogância, como defende José Carlos dos Anjos, que tem como base os valores de uma cultura europeia cristã que justificou a escravidão, o extermínio ameríndio, o racismo, o certo e o errado, valendo-se da religião, da ciência e da lei, sem ao menos buscar entender a cosmologia do Outro como sendo igualmente válida (Anjos, 2015). Por isso mesmo, como enfatiza Cauê Machado (2015), "a lei em questão faz parte de um antigo e ininterrupto projeto genocida das populaçôes e/culturas minoritárias, sejam elas de matriz africana, ou as culturas ameríndias."

Todo este etnocentrismo e o consequente negacionismo da alteridade religiosa esteve presente, de forma direta ou indireta, quando os deputados evangélicos referidos tomaram a iniciativa de proibir a imolação sacrificial de animais pelas religióes de matriz africana. Mais especificamente, podemos avançar a hipótese da existência de uma razão explícita, aberta e declarada nos projetos dos deputados evangélicos, qual seja, a de proteger os animais e não lhes impingir sofrimento, mas também, de uma razão latente, escondida, subterrânea, não explicitada, assumida de forma plena ou parcialmente consciente, qual seja, a de eliminar as religióes de matriz africana posto que “sem sacrifício não existe religião de matriz africana” (Machado, 2015). 
É nesta perspectiva que podemos inscrever as tentativas dos deputados evangélicos do parlamento estadual do Rio Grande do Sul de eliminar o sacrifício de animais nos rituais afrorreligiosos, como sendo uma política "cristofascista". Ou seja, de forma deliberada ou enviesada, os deputados cristãos agiram baseados exclusivamente nos seus próprios princípios religiosos, tidos como modelares e superiores, e, assim sendo, adotaram uma atitude arrogante, combativa e autoritária, tentando eliminar uma cosmologia religiosa por decreto (Anjos, 2015).

\section{MobilizAÇóES AFroRRELIGIOSAS}

Durante os dois anos em que o primeiro projeto esteve em discussão na Assembleia Legislativa e no Tribunal de Justiça do Estado, bem como durante o ano em que o segundo projeto tramitou no parlamento estadual, "a mobilização dos afro-religiosos foi retumbante" (Tadvald e Gonzaga, 2017, p. 259). Ou seja, eles não se mantiveram passivos diante das tentativas de negação do direito à liberdade religiosa.

A mobilização ocorreu em várias frentes. Foi acionado o repertório de recursos simbólicos vigentes nas próprias religióes de matriz africana para solicitar a intercessão das divindades na resolução dos impasses. Trata-se de uma cosmopolítica implementada no interior dos terreiros, onde rituais a determinadas divindades, como Xangô, o deus da justiça, e Exus, receberam inúmeras ofertas e pedidos para iluminar os agentes políticos e jurídicos a agirem no sentido de impedir que uma violência tão agressiva contra a religiāo obtivesse êxito.

Foram também recorrentes as reunióes realizadas no interior dos terreiros e nas sedes das federaçóes afrorreligiosas ${ }^{15}$. Em todos os encontros eram

15 Refiro-me à atuação forte realizada pelo Conselho Estadual de Umbanda e Cultos Afro-Brasileiros, pela Federação Afro Umbandista e Espiritualista do Rio Grande do Sul, pela AFROBRAS, pela Associação Afro Umbandista de Esteio e, sobretudo, pela Congregação em Defesa das Religióes Afro-Brasileiras. 
pensadas e discutidas estratégias de ação. Pessoas eram escaladas para procurar os deputados e explicar o significado dos rituais sacrificiais; outras eram incentivadas a procurarem as rádios e demais mídias para esclarecer à sociedade que a imolação de animais ocorre somente em contexto ritualístico sem provocar sofrimento, os quais, uma vez imolados, servem de alimento para os participantes dos rituais; eram discutidos o passo a passo das mobilizaçóes que se faziam necessário, segundo o andamento dos projetos.

Mas, além disso, ocorreu a implementação de ações políticas fora dos terreiros. Em inúmeras oportunidades e em distintos espaços públicos, os membros das religióes de matriz africana compareceram paramentados com suas vestimentas sagradas. Assim, toda vez que os projetos entravam na ordem do dia para serem discutidos, na Assembleia Legislativa ou no Tribunal de Justiça do Estado, assim como no Palácio Piratini, sede do poder executivo estadual, lá estavam eles marcando presença. E nos períodos conturbados dos eventos envolvendo os projetos de lei, foram expressivas as manifestaçôes em parques e praças da capital do estado, como na Praça da Matriz, defronte a catedral metropolitana e a assembleia legislativa, e em frente ao Mercado Público Municipal e o Paço Municipal. Em tais ocasióes utilizaram carros com equipamento de som e portaram cartazes que denunciavam os projetos como atos de intolerância religiosa e de racismo religioso. Em alguns momentos, sobretudo em vésperas de votaçóes, montaram tendas e permaneceram acampados durante alguns dias na Praça da Matriz, exibindo faixas e cartazes de protesto. Em outros momentos, como no auditório da Assembleia legislativa, quando foi possível, tomaram a palavra para defender os seus direitos.

Nesse período ocorreu a formação de uma verdadeira "frente afrorreligiosa” - composta por líderes afrorreligiosos e por membros de entidades e militantes do Movimento Negro Unificado, da Coordenação Nacional das Entidades Negras e do Conselho Estadual de Desenvolvimento da Comunidade Negra do Rio Grande do Sul - para conduzir as mobilizaçóes nos espaços públicos. 
É significativo que na passagem da primeira para a segunda tentativa evangélica de proibir a imolação de animais ocorreu a criação de uma importante associação afrorreligiosa no Rio Grande do Sul. Após muitas conversas e negociaçôes com o governo estadual, incrementadas sobretudo a partir de 2011, quando Tarso Genro (PT) assumiu o governo do Estado por quatro anos, foi criado, em junho de 2014, o Conselho do Povo de Terreiro do Estado do Rio Grande do Sul (CPTERS). Decretado pelo governador, o CPTERS surgiu com a finalidade de "desenvolver açóes, estudos, propor medidas e políticas públicas voltadas para o conjunto das comunidades do povo de terreiro do Estado, caracterizando-se como um instrumento de reparação civilizatória, na busca da equidade econômica, política e cultural e da eliminação das discriminaçôes" ${ }^{\prime 16}$.

Essa atitude por parte do governo estadual mostra que o Estado pode ser agente de discriminaçáo, como apontamos anteriormente, mas pode também ser agente de apoio às minorias religiosas, no caso, as afrorreligiosas.

Hoje o Conselho do Povo de Terreiro do Estado do Rio Grande do Sul é presidido por Baba Diba de Yemonjá, importante líder porto-alegrense nas lutas contra o racismo religioso, e congrega diferentes federaçóes e agentes afrorreligiosos do Estado. Aliás, desde a sua fundação, a atuação política do Conselho foi muito importante tanto para a mobilização dos afrorreligiosos em marchas e manifestaçôes públicas, quanto na interlocução com o poder público. Foi sobretudo graças a esse Conselho, que marcou forte presença no enfrentamento

16 Segundo Tadvald e Gonzaga (2017, p. 256), "tratou-se de iniciativa pioneira na política nacional e pode ser vista como um marco deveras relevante para as negociaçóes entre os afrorreligiosos e o poder público. Cabe lembrar que a criaçáo do conselho, apesar de pioneira, inseriu-se numa agenda maior de políticas públicas nacionais que visavam a reparação de danos históricos causados à população negra no processo de formação e de desenvolvimento da sociedade brasileira”.

Para maiores informaçóes sobre o referido Conselho, como sua estrutura organizacional e atividades desenvolvidas ver Cunha, 2017, sua página no Facebook (https://www. facebook.com/cptergs/) e o decreto oficial de sua criação no site http://www.al.rs.gov. br/filerepository/repLegis/arquivos/DEC\%2051.587.pdf. 
da segunda tentativa de proibição do sacrifício de animais, que a mesma, como vimos, nem chegou ao plenário da Assembleia Legislativa.

A este propósito vale registrar que logo após o segundo projeto de lei da deputada Becker ter sido protocolado na Assembleia Legislativa, o Conselho do Povo de Terreiro emitiu uma nota contundente, na qual denunciava claramente tratar-se de uma ação racista. Diz a nota: "Fica evidente que a deputada não quer proteger os animais. Acreditamos que se fosse a intenção da parlamentar legislar a favor dos animais não se deteria exclusivamente a cercear a liberdade de culto e de práticas tradicionais dos povos e comunidades de matriz africana. Pensamos que ela deveria estar na porta dos frigoríficos, dos rodeios, dos abatedouros, das churrascarias protestando. Mas não está. Certamente o racismo está implícito nesta ação [...]. É inconstitucional, pois fere diversos marcos legais, incluindo os artigos $5^{\circ}$ e $19^{\circ}$ da Constituição Federal; seu argumento é racista e seu propósito é a intolerância religiosa (CPTERS, 2015, grifo do autor)”.

\section{As "POLÍTICAS DOS TERREIROS"}

Como vimos, os afrorreligiosos do Rio Grande do Sul entenderam que os projetos de leis constituíam não somente um ato de intolerância religiosa, mas de racismo religioso. Por isso mesmo, empreenderam um conjunto de açóes que mobilizou inicialmente os membros das religióes afro-gaúchas e logo se ampliou para várias instituiçôes e organizaçóes. É o conjunto de mobilizaçóes e articulaçóes - realizadas tanto nos recintos sagrados com a implementação de uma cosmopolítica própria, quanto no espaço público e nos recintos estatais com o acionamento de estratégias de produção de visibilidade e de defesa dos seus direitos - que induz relaçóes de força e de poder, que denominamos de "políticas dos terreiros".

Babalorixá Diba de Yemonjá, atual presidente, como foi mencionado, do Conselho do Povo de Terreiro do Estado do Rio Grande do Sul, sintetizou numa frase a importância dos terreiros para a implementação 
das "políticas dos terreiros". Disse ele: "A partir dos terreiros podemos construir políticas de igualdade racial não só para o povo de terreiro, mas para o povo negro" (Tadvald e Gonzaga, 2017, p. 260).

Ou seja, o terreiro foi o local por excelência onde esse grupo religioso pensou, conversou, discutiu e debateu mobilizações e estratégias de ação, ou seja, planejou a sua política contra a política "cristofascista". Isto porque do terreiro deriva a energia para ação e a potência para defender publicamente os seus direitos. Assim sendo, apropriando-me da concepção nativa, evidenciada na fala de Baba Diba, a referência às "políticas dos terreiros" remete a um espaço concreto e simbólico do qual emanam disposiçóes políticas para gritar pelo direito à liberdade religiosa, para denunciar o racismo e para construir, como frisou Baba Diba, políticas de igualdade racial para o povo de terreiro e para o povo negro.

É importante ressaltar que as "políticas dos terreiros" não se restringiram à luta pelo impedimento das aprovaçóes dos projetos na Assembleia Legislativa. Elas alcançaram o poder executivo estadual sobretudo com a criação do Conselho do Povo de Terreiro do Estado do Rio Grande do Sul, vinculado à Secretaria de Direitos Humanos e Cidadania do Estado, com o objetivo de produzir políticas públicas que busquem equidade econômica, política e cultural e a eliminação das discriminaçôes em relação ao Povo de Terreiro ${ }^{17}$.

Assim, o Conselho do Povo de Terreiro do Estado do Rio Grande do Sul remete às "políticas dos terreiros", em primeiro lugar, enquanto resultado de debates e reflexôes realizadas pelos interessados no sentido de unirem suas forças - "Unidos somos fortes!" foi o lema das mobilizaçóes que culminaram na criação do Conselho - para lutar contra o racismo institucional no Rio Grande do Sul. E, em segundo lugar, enquanto uma instituição que não consistiu numa mera "concessão governamental”. Ao

${ }^{17}$ Segundo Janine Maria Viegas Cunha (2017, p. 14), o Conselho do Povo de Terreiro do Estado do Rio Grande do Sul constitui um "grupo organizado politicamente para dialogar diretamente com o Estado em prol de sugerir ações, denunciar infrações e elaborar políticas públicas, enfrentando as demandas específicas do Povo de Terreiro, principalmente no que se refere à intolerância religiosa, ao racismo religioso e à violência". 
contrário, o Conselho "é o resultado explícito de um movimento que, pelo menos desde 2011, mantém negociaçốes constantes entre o Povo de Terreiro e o governo do Estado do Rio Grande do Sul" (Tadvald e Gonzaga, 2017, p. 256).

\section{CONSIDERAÇÓES FINAIS}

O texto de Ana Paula Miranda tem as lentes abertas para a realidade nacional - ao discorrer sobre as violências "cristofascistas" contra as religióes de matriz africana e sobre as "políticas dos terreiros" em resposta a elas - ao mesmo tempo em que efetua uma análise detalhada de eventos particulares que giram em torno dessa questão, ocorridos em diferentes cidades e estados brasileiros.

Esse texto, por sua vez, versou sobre a violência religiosa contra as mesmas religióes, mas se circunscreveu a um ataque específico, mas reincidente, num único estado da federação. Porém, segundo minha percepção, tanto no artigo de Miranda quanto neste fica evidenciada a potencialidade das "políticas dos terreiros" contra as políticas "cristofascistas". Ao mesmo tempo, parece claro que estas últimas políticas constituem manifestaçóes de ideologias raciais de discriminação étnico-religiosa enquanto prolongamento na atualidade de posturas e práticas próprias do sistema escravocrata. O que significa, como afirma José Carlos dos Anjos,

que a escravidão não passou completamente, que artefatos e disposiçôes corporais asseguram na longa duração a transformação das séries, sua dispersão numa multiplicidade de formas, a repetição sob a diferença. Diremos então que as formas da escravidão são sempre diferentes, mas a produção racista da realidade das raças se estabelece na longa duraçâa” (Anjos, 2019, p. 517). 


\section{REFERÊNCIAS}

ANJOS, José Carlos dos. Brasil: uma nação contra as suas minorias. Revista de psicanálise da SPPA. Porto Alegre, v. 26, n. 3, p. 507-522, dez. 2019.

ANJOS, José Carlos dos. Os sentidos do sacrifício na religiosidade afro-brasileira. [S.I.], 2015. Disponível em: http://www.ufrgs.br/ner/index.php/estante/ visôes-a-posiçôes/69-os-sentidos-do-sacrificio-na-religiosidade-afro-brasileira. Acesso em: 16 maio 2021.

CAPONE, Stefania. A Busca da África no Candomblé: tradição e poder no Brasil. Rio de Janeiro. Contra Capa Livraria; Pallas, 2004.

CORREA, Norton. Sob o signo da ameaça: conflito, poder e feitiço nas religiōes afro-brasileiras. 1998. 302 f. Tese (Doutorado em Ciências Sociais) - Pontifícia Universidade Católica de São Paulo, São Paulo, 1998.

CUNHA, Janine Maria Viegas. Conselho do povo de terreiro do Estado do Rio Grande do Sul-CPTERS: Protagonismo e Ação Política do Movimento do Povo de Terreiro do RS. 2017. Monografia de conclusão de curso (Ciências Sociais) - Universidade Federal do Rio Grande do Sul, Porto Alegre, 2017.

GIUMBELLI, Emerson. A Presença do Religioso no Espaço Público: Modalidades no Brasil. Religião \& Sociedade, v. 28, n. 2, p. 80-101, 2008.

GOLDMAN, Marcio. A construção ritual da pessoa: a possessão no Candomblé. In: C. E. Moura (org.). Candomblé: desvendando identidades. São Paulo: EMW Editores, 1987. p. 87-119.

HOSHINO, Thiago de Azevedo Pinheiro; BUENO, Winnie. "RE 494601: o reconhecimento do racismo religioso?”. JusDh, Brasília, 4 de abr. de 2019. 2019. Disponível em: http://www.jusdh.org.br/2019/04/04/re-494601-o-reconhecimento-do-racismo-religioso/. Acesso em: 7 maio 2021.

LAYTANO, Dante de. Os africanismos no Dialeto Gaúcho. Revista do Instituto Histórico e Geográfico do Rio Grande do Sul, ano 16, n. 6, 1936. 
LEISTNER, Rodrigo Marques. Entre discursos e rituais de sacralização: a polêmica da imolação de animais nos terreiros afro-brasileiros. 44a Reunião Anual da ANPOCS, 2020.

MACHADO, Cauê Fraga. A proibição do sacrifício em religióes de matriz africana e o genocídio cultural. 2015. Disponível em: http://www.ufrgs.br/ ner/index.php/estante/visóes-a-posiçôes/69-os-sentidos-do-sacrificio-na-religiosidade-afro-brasileira. Acesso em: 16 maio 2021.

MAGGIE, Yvone. Medo do feitiço: relaçōes entre magia e poder no Brasil. Rio e Janeiro: Arquivo Nacional, 1992.

MELLO, Marco Antonio. Reviras, Batuques e Carnavais: a cultura de resistência dos escravos em Pelotas. Pelotas: Editora Universitária da UFPel, 1995. MIRANDA, Ana Paula Mendes de. A "política dos terreiros" contra o racismo religioso e as políticas "cristofascistas". Debates do NER, Porto Alegre, ano 21, n. 40, 2021.

OLIVEIRA, Cristina Godoy Bernardo de. Supremo Tribunal Federal corrige injustiça histórica. Jornal da USP, São Paulo, 5 abr. 2019. Disponível em: https://jornal.usp.br/artigos/supremo-tribunal-federal-corrige-injustica-historica/. Acesso em: 10 maio. 2021.

OLIVEN, Ruben George. A parte e o todo. A diversidade cultural no Brasil-Nação. 2. ed. Petrópolis: Vozes, 2006.

ORO, Ari Pedro. O atual campo afro-religioso gaúcho. Civitas, Porto Alegre, v. 12, n. 3, p. 556-565, 2012.

ORO, Ari Pedro. O Sacrifício de animais nas religiōes afro-brasileiras: análise de uma polêmica recente no Rio Grande do Sul. Religiäo \& Sociedade, v. 25, p. 11-31, 2005.

ORO, Ari Pedro; CARVALHO, Erico; SCURO, Juan. Religiōes afro-brasileiras: uma polêmica recorrente no Rio Grande do Sul. Religião \& Sociedade, v. 37, n. 2, p. 229-253, 2017. 
PRANDI, Reginaldo. As religiōes afro-brasileiras e seus seguidores. Civitas. Porto Alegre, PUCRS, v. 3 n. 1, p. 15-34, 2003.

SANCHEZ, Wagner Lopes; ARRUDA, Glair Alonso. Novas faces do Cristofascismo no governo de Jair Bolsonaro. Revista Eclesiástica Brasileira, Petrópolis, v. 80, n. 316, p. 353-372, maio/ago. 2020.

SILVA, Gilberto Ferreira da; SANTOS, José Antonio dos; CARNEIRO, Luiz Carlos da Cunha. RS Negro, cartografias sobre a produção do conhecimento. Porto Alegre: EdiPUCRS, 2008.

SÖLLE, D. Beyond Mere Obedience: Reflections on a christian ethic for the future. Augsburg: Augsburg Publishing House, 1970.

TADVALD, Marcelo. Direito litúrgico, direito legal: a polêmica em torno do sacrifício ritual de animais nas religiôes afro-gaúchas. Caminhos. Goiânia, v. 5, n. 1, p. 129-147, jan./jun. 2007.

TADVALD, Marcelo; GONZAGA, Francisco Abrahão. O Conselho Estadual do Povo de Terreiro: religióes afro-brasileiras e políticas públicas no Rio Grande do Sul. Ciências Sociais Unisinos, São Leopoldo, v. 53, n. 2, p. 253-261, maio/ago. 2017.

Recebido em: 15/07/2021

Aprovado em: 15/07/2021 
